\title{
Tristan Garcia's Electric Ontology: Thought and its Deracinated Image
}

\author{
Review by Ekin Erkan \\ The New Centre for Research \& Practice
}

Garcia, Tristan. The Life Intense: A Modern Obsession. Edinburgh University Press, 2019.

Tristan Garcia, much like Deleuze, works within the scenographies of process philosophy and machine ontology, albeit his methodologies deny simplistic comparison(s). While, for Deleuze, the (third) synthesis of conjunction shows how a machine is always more than its parts and/or environments (because it cannot be reduced to its generators), according to Garcia's two-sided machine ontology, it is always less. Before fully exploring Garcia, however, let us briefly recall the necessary disparity between ontological status and existential status in Deleuze's machine ontology: every machine is equal within Deleuze's flat ontology qua the fourfold of body, Idea, partial object(s), and qualities. For Garcia, on the other hand, machines are existentially - or, following Garcia's parlance, "objectively" - produced through specific puissance and vary in their actualizations relative to other specific machines. Therefore, Garcia's ontology "[c]aptures entities in their formal being on the one hand and their objective being on the other" (Kleinherenbrink 239). Garcia ardently opposes reductionism, while balancing units, properties, and ensembles in congruity. However, for Deleuze, qualities are not machines but actualizations of a machine-for instance, the color "red" is not a machine in itself but an actualization. Applying this example to Garcia, "red" is granted the same ontological parity as the machine that actualizes it and is, therefore, also a machine.

Under the rubric of "compactness," Garcia's Form and Object: A Treatise on Things, (the first of Garcia's philosophical tripartite collection and recently translated from French into English), rejects all varieties of substantiality or essence-for Garcia, to endow reality with any kind of positive and self-adequate content means to constitute it with being both a whole and the component of that whole, resulting in a logical paradox (Garcia 2014,73 ). For Garcia, properties play perhaps the most critical role in respect to determining an object's unity. Such is Garcia's processual comprehension of "de-determination," the grasping of machines in their irreducibility and through a formal plane of reference (5). For instance, an observer de-determines a tree by abstracting it from its components, its environment, its properties, its past, and its future. As a machine ontology that-contra Deleuze's distinction between machines and their actualizations-removes all actuality pertaining to an entity, Garcia's system of being generates an entity alongside "everything that an entity manifests to others" (Kleinherenbrink, 237). According to Garcia, the observed tree is therefore left de-determined and reducible to itself, by which we mean it is not reduced into pure "nothingness" and, simultaneously, not reduced into "natural, social, or historical” referents (Garcia 2014, 8). Unlike Deleuze, Garcia does not consider such solitary "machines" as having any real being "in itself." For Garcia, ontological status is produced negatively and is irreducible, a byproduct of the "difference between that which is in this thing and that in which this thing is" or the "difference between $[\ldots]$ content and container" $(13,61)$. What Garcia calls "form" is the outline of an object's inclusion in a comprehension-system, the point where "something else takes over" and frames the machine. Thus, "objecthood" 
compliments "form."

Garcia remarks that "things that enter into another thing, which in one way or another comprehends them, we call 'objects'” (100), taking us one step further than Markus Gabriel's ontology of the infinite deferral of specification. For Garcia, any particular entity is not "nothing" for it is irreducible to all that composes it (e.g., atoms, sensations, thoughts, etc.) and what it features in (e.g., an apartment room, building, neighborhood, and so on). Rather than having any features "in and of itself," an entity is characterized through the pure difference between its composite make-up, or its components, and its referential background, or that in which it features. What this demonstrates is that there is no necessary composition for an object but pure relation-hood, or "intensities." Such intensities occupy Garcia's second book in the series, The Life Intense: A Modern Obsession. Here, Garcia remarks that, "[l]ike a reflection on the surface of water, a tree that is identical to itself is nothing but an effect of the profound reality of that which is, continuous variations of being, lines of becoming that momentarily appear like stable objects in space" (Garcia 2018, 81).

Notably, Garcia is a graphical philosopher, abrading linealities and differentiation while parsing our order of visual culture according to the metric of intensification, which allows for Garcia to distinguish both a politics and a history. Thus, Garcia's ontologization is significantly closer to Levi R. Bryant than Graham Harman or Timothy Morton. Garcia's work cannot be anchored to either Kant or Hegel (nor does Garcia assail the contributions of either philosopher, unlike others within the "speculative realist" camp), although both philosophers exert significant influence over Garcia's treatment of metaphysics. Following Hegel's response to the paradox of knowledge and ideation, or the conception of reality versus its appearance, metaphysics has been widely regarded as the material universe becoming conscious of itself. If Hegel's conclusion in Phenomenology of Spirit is that thinking allots being-hereby countering Kant's phenomenal/noumenal distinction-Garcia tasks the transcendental order with an apperceptual impasse: how must the world be structured such that we navigate its annals according to the constitutive process of re-identifying entities qua differentiation? In Form and Object, Garcia's flat ontology treats this injunction by outpouching metaphysics to the question of self-reference. In The Life Intense, intensity-the latticework and theoretical fulcrum upon which Garcia's incisive analysis rests - is graduated according to historical questions of beauty, truth and goodness. For Garcia, beauty is both the intensification of an object and that which introduces the ontological disparity of the "irreducible." In turn, Garcia's ethics are likewise tethered to an aesthetic order: for Garcia "goodness" is predicated upon "the beautiful."

Both Garcia's and Bryant's anti-reductionist aesthetics are directed by becoming, proper, which is determined by what analytic philosophy succinctly terms "emergent properties." As such, any object-whether it be an artwork, furniture, or a natural organism - is not determined merely by its physical parts. That is, it is neither the material stretched canvas nor the striated marks of paint that ontologically qualify the painting's (be)coming into existence, for, if this were truly the case, the artwork could be reduced to such parts. According to Bryant, the virtual is an inextricable field that engages objects in unique metaphysical processes of "becoming-emergent," prompting an order of exchange between differentiation and comprehension that results in "local manifestations." Rather than a bare substratum, the virtual is a system of the organizing and actualization of operative power, understood here as a "phase space":

[a] phase space is a set of points that can be occupied in a series of variations. For example, as a pendulum swings back and forth, it passes through a series of points between two maxima and a minima. Each of these points is a point in phase space. Moreover, none of these points are ever occupied all at once. (Bryant 56) 
For Garcia this eventual topos of enaction is, similarly, part of an operative negotiation, whereby the identity of an object is determined by its novel capacity to exhibit properties when interacting with other objects. This is a relative process of unfolding virtualities and processes, a procedure that blossoms vis-à-vis an aporetic wresting of apperception. As with Bryant's "phase space," Garcia's conception of intensity demonstrates how qualities and properties can be understood as local manifestations, or points, that predetermine any capacity for actualization.

Garcia commences with his project by tracing how the perspective of salvation or wisdom that characterized antiquity has today been "replaced by the simulation or progress of our entire being, right up to its electrification [...] the secret principle of our judgments, our immense hidden a priori" (14). Surveying contemporary technologies, culture, and technics, Garcia plucks advertisements that prompt the "explicit expression of this intoxication of sensation," choosing artifacts where the prospect of a kind of "enhanced perception" is indistinguishably wedded with the measurable. For Garcia, the incalculable has developed in tandem with the sensual: "[c]hocolate (' $86 \%$ intense'), alcohol ('intense vodka'), ice cream bars ('Magnum Intense')" (6). The project of modernity is that of a becoming-intense, which entails not only the rationalization of knowledge-production and its exchange but, simultaneously, the mathematization of the real, which suggests the tyranny of scalar overdetermination vis-à-vis the fantasy of a mathesis universalis.

Within our epochal moment of postmodernity (which ought not be conflated with postmodernism, a moment which we have arguably well passed) measurement and quantification have found new heights through intensity. The "aesthetic intensity" that Garcia maps out with a collection of contemporaneous cultural references eclipses the classical canon of beauty. Exacting an order of asymmetry, today's visual media usurps any pre-existent linkage between representation and its ideal ruled by laws of "symmetry, harmony and agreement" (10). Citing art historical moments that are often associated with the rift between modernity and postmodernity, Garcia mentions the "happenings" that proliferated in the 1960s, Viennese Actionism, and the Living Theatre. These developments illuminate how the contingency of representationally-bound visual culture, which had already discovered appropriation but was just teetering upon intermedia, was abruptly rescinded for "the shock of the presence of things" (10). Following Garcia, intensity has not only come to define aesthetic consciousness but, in turn, is precisely that which rules over our ethical consciousness as well, formulating an ethos of being.

The phenomena of intensity is diffracted and diffused within our order of algorithmic governmentality. Consider the predictive patterning algorithms that (pre)determine financial investments, drone warfare, and biometrics such as "elastic graph bunching" facial recognition technologies. What Garcia terms "variable intensity, a sine-wave of social electricity - that is, an approximate measurement of the degree of individuals' collective excitation" (12) -is evinced as the modality that dualizes our media landscape with social life. Garcia's intensity is not relative to Heideggerian unconcealement (Unverborgenheit), where facticity and scientificism is always epochally retrofitted, but is, instead, isochronal. Thus, Garcia's Geist is galvanized, volatile, and infected with action-potential circuitry.

Garcia's The Life Intense is most incisive when it revels in genealogic wander-lines. Beginning with Francis Hawksbee, an eclectic 18th century English experimentalist who produced novel work on electricity and electrostatic repulsion, Garcia traces intensity's becoming-artifactual, or its emergence into media. Garcia recounts electricity's physiological turn, with electricity understood as a vital force. Steeped within Garcia's keen historical relay, we see how the capacitor became organic with physicist Pierre Bertholon and biologist Luigi Galvani's theorization of animal electricity (or "animal magnetism"). Similarly, the electric typewriter, displacing the manual typewriter, allowed for the fluid transmission of movement and accelerated grammatization. Comparing the 
machinic assemblage of hydrology with the "quasi-invisible" electric current, Garcia writes that the electric current was "first imagined as an occult fluid partly hidden from human perception" (23). As electricity was culturally diffused, it eventually became a perceptible revelator intended for the public forum. Considering the rise of reticulated electric systems, Garcia remarks on a parallel phenomenon - the "intoxication" with light (lumière) manifest in cinematographic images, electrical light, and television:

[l]ike blood coursing through the veins of society, electric light spread through optical science and [...] broke the image into a thousand bites of light [....] Little by little, humanity forgot the electric nature of those entities, but the idea remained in the bloodstream. (19)

Thus, intensity's telos is an inflected process: permeating light and machines, alike, it becomes biologized as a kind of innate vitalist force, cradling extensity and capturing the insensible.

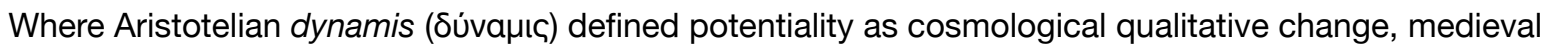
Scholasticism regarded it as the latitude of forms qua passive interiority. As Garcia's dexterous genealogy of force and physics demonstrates, this internal gradient was disrupted by both Descartes' revelatory notion of matter as pure extension and (most markedly) with Newtonian physics' explanation of measurable physical change. However, recall Newton's bifurcated quantification of movement: inertia, or "force from within," and pressure, or "force from outside." Here, force remains a metaphysical principle and no proof can validate its independent existence; "[f]orce is a phantom" (38). In kind, Garcia's "pure intensity" is something akin to a sentiment, given form by the necessary terms for its extension; externalization is a conversion of intensity, or a becoming-imagistic. This process sees reality's being mapped onto its imag-ination, so as to conceive of intensity as a differential. For Garcia, the principal lasting effect of modernity has been detaching transcendence from the absolute formulation of existence and replacing it with the ethical embrace of a civil regime in which the majority latches onto a logic of incessant fluctuation-cum-progress - this is the vital principle that stimulates intensity's electrical flux. Condemned to hyperbolic increase, intensity surges as history moves forward.

Conceiving of desire as imagistic, or mediate, and the intensive as immediate but not successive, Garcia's "intensity" occupies a transcendental order, as "[i]t is what has a size but cannot be rendered numerically," and can "change without corresponding to a series of distinct states" (46-47). As a qualitative magnitude of subjective experience (as it relates to the interior experience of perception), intensity indicates a homology between the Kantian operation of phenomena and Garcia's perceptive understanding of the world through non-formal knowledge, implicating and charting pure consciousness over an object through reason and contiguity rather than that which is discrete and measurable. Intensity is opposed to extensity and, for Garcia, "the real becomes an intensive replenishment of the subject's consciousness" (46).

As Garcia recalls, Bergson's consideration of qualitative and continuous multiplicity is dormant in this rendering. Bergson's theory of duration is opposed to quantitative, discrete, and numerical multiplicity - thus, it is very much attuned to Garcia's understanding of intensity. Recall that in Time and Free Will (1889), Bergson provides a description of the quantitative as that which "'takes up space,"” whereas the qualitative "'escapes spatialization,"” becoming internalized as a kind of "authentic intensity," or pure duration (la durée) - an indistinct and heterogenous state of the indivisible multitude (Bergson quoted in Garcia, 50).

Garcia recalls the image of flashing electricity, remarking that what is lost in thinking of intensity as an exception to 
extension and anchoring it in subjectivity is that the image is uprooted of its violent discharge. Thus, intensity is converted into an image, becoming something indomitable that simply cannot be comprehended by thought despite the fact that it is represented as such. Much like Garcia's "flashing image" of electricity, in Cinema 1: The Movement-Image Deleuze similarly considers cinema's logic of relative structuration and extensity to reify Bergson's model of duration-cum-pure multiplicity. As described in Cinema 2: The Time-Image, intensity sees its structural capture made temporal through editing, where post-WWII cinema invokes the enveloping of incompatible images, disjunct sounds, and, consequently, incompossible worlds that are-through editing -brought in-common. Much like Garcia theorizes intensity through electric flux and dis-media, birthed in cognitive image-making, contemporary Deleuzian cinema theorists such as Gregory Flaxman and Patricia Pisters have further explored this notion of the neural cinematic locus in The Brain is the Screen (2000) and The Neuro-Image (2012), respectively.

Garcia also examines the central nervous system's electric excitation as the essential demonstration of Western modernity's asymptotic intensification, heralding the figure of the libertine as the inaugural embodiment of modernity's aperture. According to Garcia's genealogical review, there is a direct phyletic line that begins with eighteenth-century aristocrats' libertine experimentation, is inflamed by nineteenth-century enlightened bourgeoisie subjects' swarming Romanticism, and reaches its epitomal status with the twentieth century model of the "rock n' roll" musician wielding an electric guitar. However, it is J.M.W. Turner's painting, Venice, the Piazzetta with the Ceremony of the Doge Marrying the Sea (1835), that Garcia lauds as the sociocultural artifact of networked intensity par excellence. For it is with Turner - "who painted so many tempests, snowstorms, turbulent skies and torrential rains" (72) - where the explicitly "electrical nature" of lightning bolts become manifest as lacerations splitting the sky, these concurrent tears partially illuminating the dome of Piazza San Marco and the arcades of the Biblioteca Marciana. Here, electricity is made architecturally present through the structuration of the arch, as lightning forms a bricolage between the column supports of Saint Theodore of Amasea and the winged lion of Piazza San Marco.

Most curiously, 1935 also indexes the year that Scottish inventor James Bowman Lindsay invented the first incandescent lightbulb. Consequently, not only is electricity visually manifest in Turner's painting but so too it is culturally captured within this historical moment. As a weaver of philosophical electrical threads, Garcia demonstrates that Turner's paintings of the storm over Venice function, avant la lettre, "like a sort of natural light bulb" (73), prefiguring those twentieth-century electrical instruments (epitomized, for Garcia, by the electric guitar) that color today's tempestuous voltaic landscape of sustained intensity.

Unlike the Latour-Harman tradition that so often neglects historical-materialist coordinates, Garcia is well aware of how intensity's mechanized, automated, and quantified appropriation has resulted in capitalist proletarianization and functions as pharmakon. Media artifacts, such as those of "[e]lectronic timekeeping [...] made it possible to discern minuscule segments of time that had hitherto been invisible to the naked eye" (94), producing new possibilities of knowledge production through measure. Garcia does not extol the leftist accelerationism championed by Nick Srnicek and Alex Williams's "\#Accelerationist Manifesto." In fact, for Garcia, accelerationist tools of subversive intensity and technological evolution produce a kind of additive pleasure that risks lapsing into pure addiction, thereby exhausting its politics.

Garcia conceives of the neologism "primaverism," combining the Italian word primavera, or "spring-time," with 
verismo, the aesthetic moment that reveals the truth in reality (91). While accelerationism invariably results in the conquest of the social world through technics, ultimately lapsing into a cycle of eternal returns, Garcia's "primaverism" demonstrates the dissatisfaction with accelerated progress as a socially produced pathology. "Primaverism" illuminates:

the tendency of the intense person who, dissatisfied with variation and progress, attaches supreme value to first experiences, and by extension to childhood, puberty, and early history. The 'primaverist' is one who believes that nothing is more powerful than a beginning, and that everything that progresses, grows, and develops can only decrease in intensity. Pop culture's fetish for adolescence as the true seat of human emotions is a prime example of primaverism. (Garcia 2017)

The hauntological revival of certain tendencies springs up with intensity at its core-however, instead of situating intensity as a future (as in accelerationism), "primaverism" displaces it into the past as a lost origin or source.

Philosopher Byung-Chul Han has written of intensity in terms of ennui in The Burnout Society (2010) and art historian Jonathan Crary similarly admonishes cognitive capitalism's war with sleep in 24/7 Capitalism (2013), where Crary describes today's capitalist project as producing a perfected and continuous scalar society of knowledge workers and immaterial labor. However, Garcia's interest in aggravated intensity is not only determined by dependency and the pathological but rests on an apperceptual axis. Thus, Garcia determines that intensities are experienced through their variable and qualitative sustained intensity, which "only exists for and by the organism that perceives it" (102). Controverting reductive accounts of emergent phenomena, Garcia recounts how perception begins as an electrical impulse but is redoubled through virtual perception, whereby the "intensity of an intensity" becomes subjectified and sustained through temporal passage. Thereafter, "routine" accompanies intensity, not only blunting it through atomization but, in turn, making it regulative and predictable-such is the actuarial foremen of today's aesthetics and cultural schema, which accomplishes uniformity through internal variation. Accordingly, Garcia notes that "[w]hat we have called 'electric modernity' is on its last legs and can no longer tell us how or why we continue to exist" (115). Garcia carves a political inquiry that edges upon the optical and moves beyond the "exhaustion of perceptions, experiences and ideals" (116) -reformulating an admixture that integrates Bergson, Deleuze, and Marx, Garcia prompts a return to the mental terrain, where "thought" is the last refuge of spirit.

This sort of thought, an aesthetic foray of categorizing everything through mentality, "equalizes the ontological status of all things" (118). This is how Garcia uniquely approaches Kant's Transcendental Decision and the fold of noumena, where the "in-itself" remains as an implicit "thought-object" devoid of object-hood. For Kant, noumenal reality does not correspond to empirical intuition (or Humean association) and, therefore, is designated negative or regulative use. Garcia presents us with a thought experiment, recounting that, in order to experience the flaxen "golden apple" that one can uniquely conjure in their thought, one would necessarily be confronted with the ordeal of visiting an orchard, plucking the apple, and spray-painting it a perfect golden sheen. "Can thought alone allow me to show that this tree with golden fruit doesn't really exist?" (118) asks Garcia. Following his ontological proof for the existence of God in the Critique of Pure Reason, Kant demonstrates that existence is not a "Real predicate" and, subsequently, philosophy after Kant has generally concurred that mental images are not sufficient in making ontological distinctions between that which is real and that which is not. Thought, as the great determinate of equivalency, must be bolstered both by experience and by sensory perception. Foregrounding Kantian apperception, Garcia demonstrates that unique "contradictory objects" such as a "squared circle" or a "triangular circle" are neither equivalent to one another nor do they exist in thought according to any operation outside of pure 
difference, which Garcia terms according to "intensities." That is, no two contradictions are alike.

Thus, history's fluctuating images and technologies of thought accord the progressive triumph of intensity. Not only are media archeological artifacts and phenomena-from developments in electrical measuring instruments to cinema and landscape painting - beholden to intensity's graduated historical register, but so, too, is the virtual mental image, which develops simultaneously as a kernel of becoming. For Garcia, thought is the nucleus that serves as a great equalizer and can avoid being parasited upon by intensity's material partition, or media-tion. Wresting objects from the invidious ravages of time, Garcia determines how "[o]bjects of thought have equal ontological dignity" (119), proffering a world brimming with inversions that upset variation, development, and intensity. Lifting thought while culling a world of spectral states, apperception is afforded the privilege of being oblivious to the activities of processual intensity.

In the final chapter, "An Opposing Image: Something Exists," Garcia sets a dialectic opposition between thought and life, "pitting the two against each other" (146). However, something curious transpires here: thought floating outside of its mental binder, the virtual image is resurrected as an idler of dreams. According to Garcia, the ethics of intensity has not only become archeologically manifest since the eighteenth-century but undergoes a material inflection, "tiptoed back out of our dreams" (137). The Life Intense ends with a series of undecided and interstitial aporias but, ultimately, the book's methodological annals vitalize how both history and media function within a register of ekstasis.

\section{Works Cited}

Bergson, H. Time and Free Will. Translated by F.L. Pogson, George Allen and Unwin, 1910.

Bryant, L. The Democracy of Objects. Open Humanities Press, 2011.

Crary, J. 24/7: Late Capitalism and the Ends of Sleep. Verso, 2013.

Deleuze, G. Cinema 1: The Movement-Image. Translated by Hugh Tomlinson and Barbara Habberjam, University of Minnesota Press, 1986.

Flaxman, G. The Brain is the Screen: Deleuze and the Philosophy of Cinema. University of Minnesota Press, 2000.

Garcia, T. The Life Intense: A Modern Obsession. Translated by Abigail Ray Alexander and Jon Cogburn, Edinburgh University Press, 2018.

---. Form and Object: A Treatise on Things. Translated by Mark Allan Ohm and Jon Cogburn, Edinburgh University Pres, 2014.

---. "The Intense Life: An Ethical Ideal." e-flux Journal \#87, December 2017. Web: http://www.e-flux.com/journal /87/164971/the-intense-life-an-ethical-ideal/

Han, B. The Burnout Society. Stanford University Press, 2010. 
Hegel, G. W. F., The Phenomenology of Spirit. Translated by Peter Fuss and John Dobbins, University of Notre Dame Press, 2019.

Kant, I. Critique of Pure Reason. Translated by Paul Guyer and Allen W. Wood, Cambridge University Press, 1999.

Kleinherenbrink, A. Against Continuity: Gilles Deleuze's Speculative Realism. Edinburgh University Press, 2019.

Pisters, P. The Neuro-Image: A Deleuzian Film-Philosophy of Digital Screen Culture. Stanford University Press, 2012.

Srnicek, N and Alex Williams, "\#Accelerationist Manifesto" in The Accelerationist Reader, eds. Armen Avanessian and Robin Mackay, Urbanomic, 2014.

\section{Cite this Review}

Erkan, Ekin. “Tristan Garcia's Electric Ontology: Thought and its Deracinated Image." Rhizomes: Cultural Studies in Emerging Knowledge, no. 36, 2020, doi:10.20415/rhiz/036.r03

RHIZOMES ISSN 1555-9998 ^ 230 East Hall Bowling Green State University Bowling Green, OH 43403

Editors: Ellen Berry and Carol Siegel. Reviews editor: Craig J. Saper. Technical editor: Helen J Burgess 